\title{
Community-Based Ecotourism: The Transformation of Local Community
}

\author{
Nantira Pookhao ${ }^{1}$ \\ ${ }^{1}$ Department of Hotel and Tourism Studies, Siam University, Bangkok, Thailand \\ ${ }^{1}$ School of Social Sciences and Psychology, University of Western Sydney, Sydney, Australia
}

\begin{abstract}
Community-based ecotourism (CBET) is considered a sustainable form of tourism that improves the quality of life of hosts at the tourist destination. Scholars have yet to explore the long-term operation of CBET in relation to its effects on the local way of life. Consequently, the purpose of this paper is to examine the transformation of a local community due to the operation of CBET in relation to sociocultural, economic and environmental aspects. The findings reveal that the community encounters both positive and negative impacts of transformation. However, unintended impacts of the CBET operation lay embedded in the transformation of relationships among the community members. The study identifies that close relationships among the villagers has been initially transformed to loose relationships due to forgotten communal goals; CBET has transformed from being a conservation tool to being a business-oriented goal which causes conflicts of interest among local people and alters traditional social structure. The study also agrees with the notion of social exchange theory for villagers to enhance environmental sustainability, and proposes that slight inequalities of benefits received from CBET causes social transformation at the local level.
\end{abstract}

\section{Introduction}

Technological advancement and globalisation is creating a world that is becoming a smaller place for travellers, while at the same time promoting mass tourism, which is a macro global force. As a result of mass tourism, the tourism industry is expeditiously growing by generating increased income and boosting extended employment. In 2013, the World Travel \& Tourism Council reported that the tourism sector contributed USD 7 trillion or $9.5 \%$ of global Gross Domestic Product (GDP) in the global economy and generated approximately 266 million jobs internationally. In the same direction, due to longer stays and increased spending in 2014, the tourism industry continues to grow. WTTC further forecasts that from 2014 to 2024, over 4\% growth rate is expected annually, which is predicted to create nearly 347 million jobs and account for $10.2 \%$ of total employment globally in 2024 [1]. 
Without good policy, planning and practice, tourism can be a double-edged sword. It appears to be a tool used internationally to boost the economy, particularly in developing countries. Yet tourism can massively degrade the sociocultural and environmental aspects of the tourism destination through mass tourism. Due to the deterioration at the tourism destination caused by mass tourism, alternative tourism has emerged in the 1980s and sought to balance out the triple bottom line of sustainable development - the social, the economic and the environment.

Ecotourism is an alternative form of tourism regarded as a development tool that promotes ecological conservation. In practice, scholars have shown that ecotourism does not genuinely produce greater sustainable outcomes than mass tourism and does not focus on the wellbeing of local residents, except solely to emphasise the environmental mindset. Consequently, community-based ecotourism (CBET) endeavours to fill the gap in ecotourism by integrating the local community in the development and operational processes. Consequently, CBET seems to be a solution for local people seeking sustainability in a tourism destination.

\section{Literature review}

Regionally, Southeast Asia (SEA) tourism's direct contribution to world GDP in 2013 ranks number five after the European Union, North America, Northeast Asia and Latin America respectively [2]. In Thailand, tourism has been a source of income since World War II. According to the Department of Tourism (DOT), between 1998 and 2007 international tourist arrivals have increased from 7.8 million to 14.5 million, almost doubling in number. In 2013, a half decade later, the number of international tourist arrivals again rose, doubling to 26.5 million, and representing an increase from 2012 of $18.76 \%$ [3].

Therefore, tourism per se not only generates national income but also provides job opportunities and hard currency to the community, which are considered as positive economic impacts $[4,5]$. The stated information has proved that the rapid growth of the tourism industry is obviously perceived as a driver of socioeconomic progress, particularly in developing countries [4, 6-8] such as Thailand. Thailand yearns to boost its economy through promoting tourism. Chiang Mai, in northern Thailand, is a regional gateway city where the majority of ecotourism is based, and accounted for 6.57 million visitors and generated THB 53,863 million (approximately USD 1.660 million) in 2012 [9].

Ecotourism in the form of mountain trekking is reputable in the north of Thailand. Ecotourism in this region is interrelated with various forms of tourism such as trekking, adventure and cultural interest. The number of local villages engaging with these activities is expanding, especially in regional gateway cities such as Chiang Mai [10]. Since many communities in Chiang Mai have automatically become a part of ecotourism, a community-based approach has been introduced to local villages to enable local people to participate and have some kind of control over their surroundings. Similar to community-based tourism (CBT), the notion of community-based ecotourism (CBET) is particularly embedded with the notion of community control and involvement, and ensuring a significant proportion of economic returns. What makes CBET distinct from CBT is that CBET persistently reiterates the preservation of the ecological surrounding with the ideology of ecotourism: educational-based, nature-based, and sustainable-based [10], while the sociocultural perspective is still promoted.

Given that ecotourism emphasises educational-based and learning activities, not only is knowledge of the operation essential, but knowledge of the ecological surroundings and scientific ideas about local people's wisdom should also be developed and supported by stakeholders. Unlike in developed countries, the local community in Thailand is typically lacking in CBET-related knowledge to operate effectively. Collaboration with, and assistance from, external tourism stakeholders is therefore vital. In Thailand, ecotourism is generally regarded as a vague concept with varying understanding by the practitioners. 
Most of Thai ecotourism practice predominantly overlaps with the concepts of nature tourism. Despite the difficulty to follow of the ecotourism concepts, community-based approaches can likewise be problematic. The state agencies have questioned allowing local people to participate in managing environmental resources for tourism purposes, while the local people feel restricted from entering into forests where they used to collect food and which are presently owned by state agencies such as National Parks. Being a CBET village appears to be a long and enduring process in dealing with various agencies, not only within the country but also internationally.

Given the limited levels of education among the local people, the lack of competency and inadequacy of tourism and service facilities, the community must work enduringly with external stakeholders. Therefore, encountering, learning and participating with guests and other stakeholders have become a part of local members' lives.

Operating CBET within the community for a long period, such as over ten years, is likely transforming the local way of life in some aspects. Consequently, this study seeks to understand that transformation, and specifically whether it contributes to sustainability and quality of life.

\section{Methodology}

The Delphi technique was applied to select a case study that contains the characteristic notions of CBET. Fieldwork was conducted for one and a half months at selected CBET villages in Mae Kampong, located in Chiang Mai province in the north of Thailand. The village is an upland conservational community that represents long-term CBET operations of approximately 15 years. Ethnographic techniques were applied to identify in-depth and various dimensions of the case. Ecotourism stakeholders were interviewed prior to the researcher entering into the village.

\section{Research Context}

\subsection{Ecotourism in Thailand}

Although ecotourism was introduced into Thailand in 1974, both the government and its people have yet to embrace it fully. In the 1980s, alternative tourism (AT) was developed initially by Thailand, followed by kanthongthiao choeng anurak (conservation tourism) in 1994 and kanthongthiao choeng nivet (ecological tourism) in 1998 [11]. As a consequence of the seventh National Economic and Social and Development plan (1992-1996), the ecotourism-related policy was launched in 1993 and initially merged into the tourism policy of the Tourism Authority of Thailand (TAT) in 1995. The National Ecotourism Action Plan 2002-2006 was launched in 2001.

Part of this plan was a budget of THB 66 million (approximately USD 2 million) and 79 projects, including those that offered support to government officers to participate in international ecotourism conferences, green public relations and awareness projects or building ecotourism networks; and the creation of the Ecotourism National Board, Thai Ecotourism Association, and Ecotourism Local Committee [12].

At the same time as the ecotourism campaign, the 'Amazing Thailand' campaign was radically promoted in 1998-1999 to reach the objective of expected tourism income. The outcome of the campaign was above the estimated target. The campaign magnified the number of international tourist arrivals to Thailand, which caused environmental degradation and unsustainable development [12]. In spite of the destructive environmental impacts, TAT has continuously promoted the campaign to boost the economy of the country. Therefore, the promotion of ecotourism and Amazing Thailand at policy level was contradicted and confused.

In practice, ecotourism management within the state agencies, ministries and departments, has struggled. One reason is due to the decentralisation of tourism within the Ministry of Tourism and Sports (MOTS) between TAT and DOT (Department of Tourism), which has led to a lack of 
cooperation among ministries impacted by the inadequacy of marketing or development support for tourist destinations. The recently emerged National Tourism Development Plan (NTDP 2012-2016) continuously demonstrates the mystified strategy of sustainable development based on the Sufficiency Economy Philosophy (SEP) of Thailand's King Rama IV, versus highlighting economic improvement. The NTDP aims for Thailand to be a top five tourist destination of Asia, to drive tourism competitiveness up to 15 in world rankings and to increase tourism income by at least five percent during the five-year period [13].

This target has led Thailand to invest in tourism development in terms of billions of baht annually [14]. Again, the notion of SEP and boosting economic growth seems to be paradoxical. Despite the foreign income derived from tourism significantly contributes to the fundamental structural development within the country, such as transportation, electricity and employment, which directly and indirectly benefits local people, tourism has also created an unintended social phenomenon and unsustainable use of natural resources in Thailand $[14,15]$.

\subsection{Case Study: Mae Kampong}

Mae Kampong is a small village surrounded by mountainous terrain with 408 villagers in 132 households [16]. A hundred-year-old northern community with the unique history of highlanders, atmosphere of close kinship, cool weather all year round, appealing mountainous scenery, the refreshing Kampong river and welcoming villagers, it is a very attractive place for tourists to experience. The village is 60 kilometres away from Chiang Mai province, a famous tourist city in the north of Thailand. The weather is cool all year round given its altitude of 1,300 meters above sea level [16]. The area is covered by hill evergreen forest and mixed forest which also generates the water source of the Wang River and various small rivers and headwaters.

A community forest is situated alongside Chae Son National Park and was established in 1983 on land of 480,000 rai, equivalent to almost 190,000 acres [17]. The community forest served as a coffee farm and had forest and tea orchards, non-timber forest products, campsites and trekking routes for ecotourism. The villagers nourished their community forest by generating the firebreak in the form of gathering together (long kak), forming a code of conduct and initiating hiring of local security guards against deforestation. The Buddhist belief of the villagers in ordaining the trees played a role in forest conservation. Apart from the internal effort, cooperation with various agencies and networking amongst nearby villages was practised to prevent further diminishing deforestation.

Economically, Mae Kampong is a highland agricultural community and was famous for opium plantations. To resolve this problem, the Royal Project Foundation of King Rama IV proposed growing alternative plants, tea and coffee to the villagers with the support of continuous research and development. The Royal Project is responsible for the trading of local fresh coffee beans, dealing with the logistics and launch into the market. Tea leaf (mieang) cultivation is another source of income. Mieang is often part of the ingredients in various local dishes of the local people.

To preserve mieang for exporting, the tea leaves are steamed, followed by fermentation of up to four months in a sealed container to prevent contact with air. Mae Kampong is a distibution centre of mieang and the famous One Tambol (a sub-district) One Product (OTOP) of the village is the tea leaves pillow and ecotourism. The village has received the OTOP Village Champion Award for producing a product closely related to traditional identity. The award is appointed for excellent community participation in OTOP development. Also, the village has received various awards ranging from self-reliance to tourism.

CBET in Mae Kampong was initiated in 1999 by the village headman, Porluang (por means father and luang means public) Phommhin Puangmala (1996-2012), to cope with poverty due to the downturn in agriculture. Despite lacking in ecotourism operational knowledge, Porluang secured the patronage of the Thailand Community-Based Tourism Institute (CBT-I), academics and the Thailand Research Fund (TRF). 
The TRF granted the budget for a research project to the villagers and the organizations to conduct a project called 'the model of sustainable management in conservation tourism' at Mae Kampong, based on participatory action research (PAR). Consequently, the research project became the foundation of the current CBET operation. To expand marketing, Porluang and the ecotourism committee have continued to collaborate with various organizations.

The homestay received certification from the Department of Tourism has the capacity to host up to 80 people. The management of the homestay is a shared responsibility on rotation throughout the village. However, sharing the benefits of the homestay relies on the geographical distribution of six housing clusters called pang. Since the first, second and third pang is located away from the heart of tourism facilities, some tourists may refuse to stay in these places.

Mae Kampong Ecotourism Group has created ecotourism activities, such as trekking or traditional cooking classes, to promote environmental education and awareness of traditional culture. Groups providing ecotourism services and activities include people involved in traditional music, traditional dance, women's and domestic activities, local knowledge and wisdom, massage and weaving. Trekking is available over long and short distances. Ensuring for the uninterrupted operation of all ecotourism activities, the community has generated a code of conduct to regulate and guide residents and tourist behaviour. In relation to the reputation of self-reliance in the village, Mae Kampong has two mini hydropower dams which were established in 1981 with support from the Ministry of Energy.

The plants generate electrical power of about 40 kilowatts to the entire village. Mae Kampong has strong systematic monetary management through depositing ecotourism income into the cooperative account of the mini hydropower plants of the village. The elected village committee monitors and manages the account. Ten per cent of income from all ecotourism activities are deducted and allocated to the community savings account which is divided into three proportions: six per cent is dedicated to the Mae Kampong mini hydropower cooperative account so that villagers receive the benefits of low cost electricity; two per cent is conferred to the village development fund; and the rest goes towards payments to the ecotourism committee.

There is a transnational ecotourism enterprise that offers eco-adventure zipline canopy tours located in the village. Approximately ten per cent of the villagers benefit from this activity, and not many villagers are employed as high paid staff in this operation due to their limited knowledge of English and activity-related skills. The young and energetic English-speaking experienced staff is typically from the city. The vans routinely accompany tourists from Chiang Mai. After the two hour flying activity, the vans take the tourists to a waterfall. Consequently, the vans occupy the narrow paved streets and tourists have no chance to stroll around the village and purchase local products due to the fixed scheduled return trip to Chiang Mai.

\section{Discussion}

The findings reveal that the village has encountered both positive and negative impacts in being part of CBET. Socioculturally, unintended impacts of the CBET operation lay embedded in the transformation of relationships among community members. The study identified that close relationships among the villagers were transformed to a more loose relationship due to the forgotten communal goal - from seeing CBET as a conservation tool to CBET as a business-oriented goal. One example of this is the conflict of the tea leaves pillow group. This group has become divided into two groups due to the lack of transparency, inequality and conflicts of interest among members. The villagers who are not involved with this group also take sides based on their kin relationships.

The study also agreed with the notion of social exchange theory (SET) in tourism studies related to the increase of conservation awareness among local people and demonstrates that SET explained social phenomenon at local level. The villagers who receive direct benefits are satisfied with the way the CBET operates, while villagers who get indirect benefits, such as dividends or infrastructure development, do not fully appreciate the CBET operation and the transformation caused by tourism. For example, most of the homestay's owners can tolerate the noise of the vans and cars occupying the 
small street of Mae Kampong, while the people in pang nok, the furthest pang from the tourism centre, perceive that those vans and cars are annoying. Yet after 15 years of CBET operation, the villagers do not feel antagonistic towards tourists since community members eventually receive benefits in one way or another. This is because the control and power of the local community in managing tourists is outlined in the local code of conduct.

Many households, particularly the homestay's owners, have abandoned their local way of life in cultivating tea and coffee and solely focus on ecotourism. Some members of the next generation have decided to work with the transnational company that operates the zipline tours which is more energetic, modern and meets their desired lifestyle, while most of their peers still migrate to live in the city.

Some tourists wish to own a second home in the village and a few second homes are already located within the village area and being cared for by the villagers. Nevertheless, the demand to purchase lands near the street and river, and the actual supply of land to sell in the isolated community forest do not match. Therefore there does not appear to be a serious problem of outside invasion into the village, now or in the future.

CBET empowers local people in deciding what to hide and what to present to tourists, and can prevent the community from prospective transformation. This phenomenon indicates that tourism can preserve local culture for the next generation. Placing a postmodern perspective into the CBET context in the form of reality, back and front stage and authenticity [18-21] creates the new form of sociocultural protection within the community to distinguish the amalgamation among outsiders and insiders. Some local activities, such as gathering around a bonfire or respecting a village's sacred place, are performed on the back stage. Likewise, some rooms in the homestay are locked for privacy. Yet many children tend to copy foreigners in dressing in shorts and in a more 'sexy and modern' manner, and perceive that foreigners are of a higher and/or better class. While villages can make some places out of bounds for tourists, they cannot stop their children from copying other cultures or feeling inferior for being the service providers.

The transformation of local people is now directed towards greater environmental awareness compared to before CBET operations. Benefits received from CBET operations affect the community's attachment and involvement towards sustainable tourism development [22]. In so doing, CBET operations contributes to the benefit of conservation. Nevertheless some environmental impacts, such as the massive use of electricity and garbage derived from tourism, are still problematic for the upland village. Given its location, the village cannot burn or bury garbage as the lands contribute to the water source of the area. Despite the presence of the transnational company, economic leakage is unlikely to occur. The villagers were annoyed with the emergence of some external tourism entrepreneurs, and within the existing controls, outside tourism entrepreneurs such as hotels and resorts, were socially expelled if the owners refused to contribute towards the benefits of the village.

According to Tosun [23], CBET operations in developing countries acquire more reinforcement from outside stakeholders than in developed countries. The village therefore has encountered various stakeholders throughout 15 years of operations. Academics and government agencies are the group of people that transform the local way of life of the villagers by endorsing too many projects for villagers to participate in, which tends to promotes their (the academics and officials') own interests, and is not purely community-focused.

\section{Conclusion and Implications}

Overall, CBET is a good method for local communities to follow for further sustainability. It is true that ecological surroundings have been conserved for touristic purposes and the economic position for the whole village has improved. Nevertheless, negative sociocultural impacts are a hidden aspect of tourism. To protect the unfavourable impacts, policy-makers, particularly in developing countries, should seriously focus on the place based sociocultural aspect by authentically emphasizing the bottom-up approach. Since existing social capital, such as kin relations, intimate social relationships 
and harmony, are crucial for sustainable CBET operations, the traditional social structure should be highlighted during the developing and planning process to sustain the CBET operation, and prevent the transformation of local social structure from degrading social capital. To prevent the feeling of inferiority by being service providers and poorly educated rural people, rather than emphasizing the professional hospitality under the notion of 'the customer is god', CBET developers should emphasise the value of traditional kindness (namjai) to hosts and introduce local members to raise their children by pointing out the positive aspects of practising their local culture.

The policy-makers should further note that to educate and train local people, government agencies, academics and NGOs must provide assistance in accordance with what the community truly wants, by bestowing support long-term rather than conforming to the predetermined plan, budget or research based on temporary features. These unwanted supports can eventually deteriorate local quality of life. Finally, the paper suggests that prospective research should focus on ethnographical approaches, as more could be useful in the multidisciplinary field of tourism studies, and particularly ecotourism, which has its own anthropology of symbols in which local people culturally construct with natural attractions.

\section{Acknowledgement}

The author is a $\mathrm{PhD}$ candidate at University of Western Sydney (UWS). This research was financed by Siam University, UWS and University of Melbourne Faculty of Arts Asia Institute 2012. The study was possible by the kind support of A/Prof Robyn Bushell, A/Prof Mary Hawkins, Dr. Russell Staiff, Dr. Poll Thee, Mae Hurley, policy-makers, NGOs, academics and villagers of Mae Kampong.

\section{References}

1. World Travel and Tourism Council (WTTC), Travel \& Tourism Economic Impact 2014 World In R. Turner (Ed.), (WTTC, London, 2014a)

2. World Travel and Tourism Council (WTTC), Travel \& Tourism Economic Impact 2014 Southeast Asia. In R. Turner (Ed.), (WTTC, London, 2014a)

3. Department of Tourism (DOT), International Tourist Arrivals 2013, ( DOT, Bangkok, 2014)

4. M. Honey, Ecotourism and sustainable development: who owns paradise? (Island Press, Washington, 2008)

5. H.-S. C. Choi, E. Sirakaya, J. Travel Res.43, 380 (2005)

6. D. Harrison, Tourism and the less developed world: issues and case studies (CABI Publishing, New York, 2001)

7. J. Butcher, Ecotourism, NGOs, and development: a critical analysis (Routledge, Abingdon, Oxon, 2007)

8. W. M. Adams, Green development: environment and sustainability in the Third World (2nd ed.) (Routledge, London, 2001)

9. Tourism Authority of Thailand (TAT), 2014, Marketing database: tourism statistics in the country (Provincial data). Retrieved 15 June 2014, from

http://marketingdatabase.tat.or.th/ewt w3c/ewt news.php?nid=1621

10. D. Weaver, Tourism Geographies, 4, 153 (2002)

11. A. Leksakundilok, (Unpublished PhD thesis, University of Sydney, 2004)

12. N. Kontogeorgopoulos, Curr. Issues in Tourism 2, 316 (1999)

13. The National Economic and Social Development Board (NESDB), 2008, The National Economic and Social Development Plan. Retrieved 26 June 2012, from

http://www.nesdb.go.th/Default.aspx?tabid=402 
14. Green World Foundation, 2012, Talk to Mingsarn Kaosa-ard: When tourism means inequality. Retrieved 9 February 2014, from http://www.greenworld.or.th/greenworld/interview/1979

15. M. S. Kaosa-ard, TDRI Quarterly Review, 9, 23 (1994)

16. Subdistrict Administrative Organization (SAO), Tourism information of Mae Kampong, (Huay Kaew SAO, 2012)

17. Department of National Parks, Wildlife and Plant Conservation. (n.d.). Chae Son National Park. Retrieved 5 February 2014, from

http://park.dnp.go.th/visitor/nationparkshow.php?PTA_CODE $=1058$

18. J. Urry, The tourist gaze: leisure and travel in contemporary societies (Sage, London, 1990)

19. D. MacCannell, Amer. J. Sociol. 79, 588 (1973)

20. D. MacCannell, The tourist: a new theory of the leisure class (University of California Press, Berkeley, 1976)

21. E. Cohen, Ann. Tour. Res., 15, 371 (1988)

22. T. H. Lee, Tour. Manage. 34, 37 (2013)

23. C. Tosun, Tour. Manage. 21, 613 (2000) 